\title{
High intensity interval training in patients with COPD: A bibliographic review
}

\author{
Rubens A. Lima, ${ }^{1}$ Fátima S. Ferreira, ${ }^{1}$ Natália B. M. de França, ${ }_{1}^{1}$ Juliana R. Ferreira, ${ }_{1}^{1}$ Késsia N. A. Sales ${ }^{2 \star}$
}

\begin{abstract}
Introduction: Chronic obstructive pulmonary disease (COPD) is characterized by chronic limitation of airflow associated with a variety of pathological pulmonary changes. Pulmonary rehabilitation programs seek to improve several aspects of patients with COPD. Regarding the use of physical conditioning in approaches to COPD, High Intensity Interval Training (HIIT) is defined by high intensity interval sessions with rest sessions. Objective: To evaluate the effectiveness of HIIT in patients with COPD. Materials and methods: A narrative review of the literature was made through the Virtual Health Library databases (LILACS, MEDLINE) and PEDro, using the descriptors High Intensity Interval Training, Chronic Obstructive Pulmonary Disease and Rehabilitation, in order to obtain a synthesis on the insertion of HIIT in the pulmonary rehabilitation of patients with COPD. Articles that addressed HIIT in individuals with COPD were included and those that did not correspond to the topic were excluded. Conclusion: In spite of the need for further studies on this topic, HIIT can be used in the pulmonary rehabilitation of patients with COPD with moderate to severe airflow limitation.
\end{abstract}

Keywords: Chronic obstructive pulmonary disease; High intensity interval training; Pulmonary rehabilitation.

\section{Resumo}

Treino intervalado de alta intensidade (HIIT) em pacientes portadores de DPOC: Uma revisão bibliográfica

Introdução: A doença pulmonar obstrutiva crônica (DPOC) caracteriza-se por limitação crônica do fluxo aéreo associada com diversas mudanças patológicas pulmonares. Programas de reabilitação pulmonar visam à melhora, em vários aspectos, do paciente com DPOC. Em relação ao condicionamento físico empregado na abordagem destes indivíduos, o Treino Intervalado de Alta Intensidade (HIIT) se define por sessões de alta intensidade intervalado com sessões de repouso. Objetivo: Avaliar a efetividade do HIIT no paciente portador de DPOC. Método: Realizou-se uma revisão narrativa da literatura através das bases da Biblioteca Virtual de Saúde (LILACS, MEDLINE) e do PEDro com os descritores Treino Intervalado de Alta Intensidade, Doença Pulmonar Obstrutiva Crônica e Reabilitação, de modo a se obter uma síntese sobre a inserção do HIIT na reabilitação pulmonar do paciente com DPOC. Foram incluídos artigos que abordassem o HIIT em indivíduos com DPOC e excluídos trabalhos não correspondentes ao tema.
1. Departament of Fisiotherapy. Pitágoras Faculty. Belo Horizonte, MG, Brazil.

2. Departament of Odontology. Faculty of Basic and Health Sciences. Federal University of Jequitinhonha and Mucuri Valleys. Diamantina, MG, Brazil.

*Corresponding address:

Rua da Glória, 157

Diamantina, MG, Brasil.

CEP: 39100-000.

E-mail: sales.kessia@gmail.com

BJHBS, Rio de Janeiro, 2019;18(1):64-72

Recebido em 11/02/2019. Aprovado em 06/06/2019.

Conclusão: Apesar da necessidade de mais estudos referentes ao tema, o HIIT pode ser empregado na reabilitação pulmonar do paciente portador de DPOC com limitação moderada/ grave do fluxo aéreo.

Descritores: Doença Pulmonar Obstrutiva Crônica; Treino Intervalado de Alta Intensidade; Reabilitação Pulmonar.

\section{Resumen}

\section{Entrenamiento intermedio de alta intensidade (HIIT) en pacientes portadores de EPOC: Una revi- sión bibliográfica}

Introdución: La enfermedad pulmonar obstructiva crónica (EPOC) se caracteriza por la limitación crónica del flujo aéreo asociada con diversos cambios patológicos pulmonares. Los programas de rehabilitación pulmonar apuntan a la mejora, en varios aspectos, del paciente con EPOC. En relación al acondicionamiento físico empleado en el abordaje al DPOCítico el Entrenamiento Intervalo de Alta Intensidad (HIIT) se define por sesiones de alta intensidad intervalada con sesiones de reposo. Objetivo: Evaluar la efectividad del HIIT en el paciente portador de EPOC. Material y método: Se realizó una revisión narrativa de la literatura a través de las bases de la Biblioteca Virtual de Salud (LILACS, MEDLINE) y PEDro con los descriptores Entrenamiento Intervalado de Alta Intensidad, Enfermedad Pulmonar Obstructiva Crónica y Rehabilitación para obtener una síntesis sobre la inserción del HIIT en la reha- 
bilitación pulmonar del paciente con EPOC. Se incluyeron artículos que abordasen el HIIT en individuos con EPOC y excluidos trabajos no correspondientes al tema. Conclusión: A pesar de la necesidad de más estudios referentes al tema, el HIIT puede ser empleado en la rehabilitación pulmonar del paciente portador de EPOC con limitación moderada / grave del flujo aéreo.

Palabras clave: Enfermedad pulmonar obstructiva crónica (EPOC); Entrenamiento Intervalo de Alta Intensidad; Rehabilitación Pulmonar.

\section{Introduction}

Chronic obstructive pulmonary disease (COPD) is characterized by a limitation in pulmonary airflow. COPD is of great public importance because it is one of the major causes of morbidity and mortality in the world. It is a progressive disease that can be treated and even prevented. A high number of individuals with COPD die due to complications generated by the disease. ${ }^{1}$

Rehabilitation programs for COPD are extensive and deal with, among other factors, itssymptomatology. Pulmonary rehabilitation is well disseminated and is the gold standard for treatment of the disease, leading to a reduction of symptoms and an improvement in the activities of daily life. Because it is a chronic and progressive disease, the pharmacological and nonpharmacological treatments of this disease seek to decrease the symptomatology. ${ }^{2-4}$

Physiotherapy is part of a multimodal treatment and, in this context, uses various treatment modalities for the COPD patient, acting through pulmonary rehabilitation to improve functional capacity, increasing tolerance to exercise and promoting relief of dyspnea, thereby ultimately bringing a better quality of life to these patients. Through individual clinical evaluation, objectives will be established to promote the best treatment for each patient, and strength and resistance training may be proposed. The physiotherapist may also propose to physically prepare patients in the best way so that the new crises they may develop are less aggressive and bring fewer functional repercussions. ${ }^{2-4}$

In general, the purpose of physical therapy is to reduce dyspnea, intervening in airway clearance and promoting patient awareness and self-care, in addition to improving exercise capacity and tolerance through aerobic exercises. Studies promote the use of High Intensity Interval Training (HIIT) in patients with COPD, 1 but what are the repercussions of this training modality for these patients?

The objective of this study is, therefore, to perform a review of the main findings regarding the implantation of HIIT in the treatment of patients with COPD, while showing the physiotherapeutic approach used in the rehabilitation of these patients. It is also intended to verify the repercussions of HIIT on pulmonary rehabilitation programs in such patients.

\section{Review of literature}

\section{Chronic obstructive pulmonary disease}

The Global Initiative for Chronic Obstructive Lung Disease (GOLD), which was created in 1997 with the collaboration of the National Heart, Lung, and Blood Institute, National Institutes of Health, USA, and the World Health Organization, is an initiative that aims to prevent and treat COPD. COPD is defined as a common disease that is preventable and treatable, characterized by airflow limitation, being usually progressive in nature and associated with a chronic inflammatory response of the airways and lungs caused by harmful particles or gases. ${ }^{1}$

Chronic bronchitis and emphysema comprise the clinical entity of COPD, the former being related to a cluster of small airway diseases and the latter to the destruction of lung parenchyma. However, in most COPD patients, both conditions are due to etiologic agents, such as cigarette smoke, which affect the lungs at all levels of the airways. Emphysema is also often accompanied by chronic bronchitis and contributes to small airway obstruction. ${ }^{1,5,33}$

\section{Pathology, pathogenesis and pathophysiology}

The pathology of COPD includes chronic inflammation and structural changes resulting from the constant process of injury and tissue repair, however a correct diagnosis is necessary. The nature of the inflammatory response in COPD patients is unknown, but appears to be directly related to excess proteinase and oxidative stress generated by inhaled particles such as cigarette smoke. The pathophysiology of COPD is consistent with airflow limitation and air trapping, gas exchange abnormalities, hypersecretion 


\section{Review article}

of mucus, pulmonary hypertension, and exacerbations and systemic repercussions. ${ }^{1,3}$

\section{Symptoms}

COPD may or may not be symptomatic. The presence of dyspnea, cough (with or without sputum) and wheezing may indicate constriction of the bronchi. ${ }^{1,3,5}$

Dyspnea consists of difficulty in breathing and is reported by the COPD patient as "shortness of breath." This symptom should never be overlooked and is a strong predictor of maximum exercise capacity. ${ }^{6}$

\section{Questionnaires for COPD}

Health questionnaires in general have been created and used in order to categorize patients in relation to their health disorders through the patient's own perception. Questionnaires are important tools for evaluation and treatment, including those of pulmonary diseases.?

Different instruments for COPD, aiming at symptomatology and quality of life, can be found in the literature. The evaluation of symptomatology is commonly performed by the following questionnaires:

1. The COPD Assessment Test (CAT) is a fast instrument for quantifying the impact of COPD symptoms, consisting of eight items: cough, catarrh, tightness of the chest, shortness of breath, limitations in home activities, confidence in leaving the home, sleep and energy. The patient chooses a single response for each item, and at the end of the summation the symptoms are classified as: 6-10 points, mild symptomatology; 11-20, moderate; 21-30, severe; and 31-40, very serious. ${ }^{8}$

2. The Modified British Medical Research Council (mMRC) can be considered a scale, because patients choose the item that best corresponds to their symptomatology, in this case dyspnea. The dyspnea analyzed is subjective, and ranges from 1 (minor impact) to 5 (greater impact). ${ }^{9}$

Both questionnaires are effective in their purpose and easy to apply. Both CAT and MMRC are validated for reproduction in patients with COPD in Brazil. The first evaluates the symptoms and the second dyspnea, both complementing each other, but neither questionnaire characterizes the severity of the symptoms. ${ }^{1,8,9}$

3. The Clinical COPD Questionnaire (CCQ) is used to perform a clinical control of patients with COPD.
The questionnaire does not assess quality of life, but rather clinical impairment as a whole, aiming at specific consequences of the disease, such as symptoms and consequences related to functional and mental states. In this questionnaire, patients are requested to remember their experiences during the last week by answering 10 questions, using a scale that ranges from 0 (asymptomatic / without limitation) to 6 (extremely symptomatic / totally limited). Symptoms can be evaluated by dividing the result of items 1,2, 5 and 6 by 4 ; functional state by dividing the result of items 7, 8, 9 and 10 by 4; and mental state by dividing items 3 and 4 by 2 . The division of the 10 scores by 10 generates an overall CCQ score, which ranges from 0 (very good control) to 6 (extremely poor control). ${ }^{10}$

The quality of life of patients with COPD and their general state of health can be considered determinants for the success of the treatment, for which there are questionnaires that address these topics, such as: ${ }^{: 11,12}$

1. The Saint George's Respiratory Questionnaire(SGRQ) addresses aspects related to the symptoms, activity and psychosocial impacts that the respiratory disease brings to the individual, being validated for COPD, asthma and bronchiectasis. ${ }^{11}$

According to Sousa et al. (2000) ${ }^{7}$, each of these domains mentioned above has a maximum possible score;

(...) the points of each response are summed and the total is referred to as a percentage of this maximum. Values above $10 \%$ reflect an altered quality of life in that domain. Changes equal to or greater than $4 \%$ after an intervention, in any domain or in the total sum of the points, indicate a significant change in patients' quality of life.

2. The Chronic Respiratory Questionnaire (CRQ) consists of 20 questions, divided into four domains: dyspnea, fatigue, emotional function and self-control. In addition to having a validated Portuguese version for Brazil, it is widely used in the analysis of the general health of patients with COPD. ${ }^{12}$

The SGRQ and CRQ instruments are important tools for the evaluation of patients with COPD, being capable of evaluating the response of an intervention in other aspects that are not directly related to the disease itself. However, they are extensive questionnaires, which are difficult to replicate frequently for purposes of reassessment. 


\section{Comorbidities and exacerbations}

The comorbidities that occur most frequently in patients with COPD are cardiovascular disease, musculoskeletal dysfunction, metabolic syndrome, osteoporosis, depression, and lung cancer. ${ }^{1,5,9,10}$

According to Cardoso (2003) exacerbations can be considered as mild, moderate or severe:

Mild exacerbations can be described as those in which patients have an increased need for medication but can take care of this in their environment. In moderate exacerbations, patients have an increased need for medication and feel that they need additional medical help; (...). In severe exacerbation, patients and / or their caregivers recognize an obvious and /or rapid worsening of the clinical condition, seek care and end up requiring hospitalization.

Comorbidities, such as peripheral arterial disease, coronary artery disease, musculoskeletal decline, diabetes mellitus and metabolic syndrome, contribute as much as exacerbations to a general worsening of COPD. When properly prescribed, endurance training reduces cardiovascular disease risks even in COPD patients, and may benefit both hypertensive and obese patients. ${ }^{34}$

\section{Classification of COPD}

The classification of COPD is important in the choice of treatment, both pharmacological and non-pharmacological. The classification proposed by GOLD assesses airflow limitation, exacerbations or hospitalizations corresponding to exacerbations, and symptoms. ${ }^{1}$

Airflow limitation can be measured by the spirometry test, GOLD 1 denoting mild limitation, GOLD 2 moderate, GOLD 3 severe, and GOLD 4 very severe airflow limitation. Starting from the degree of airflow limitation, it is necessary to ascertain the number of exacerbations of the patient in the last 12 months and if hospitalization due to exacerbation of symptoms occurred within the last year. ${ }^{1}$

According to GOLD1 the COPD sufferer can, through airflow limitation, exacerbations and CAT and mMRC scores, be classified into one of the four groups below:

GROUP A - low risk, few symptoms; GOLD 1 or GOLD 2; 0-1 exacerbation per year and no hospitalization due to exacerbation; $\mathrm{CAT}<10$ or mMRC 0-1

GROUP B - low risk, multiple symptoms; GOLD 1 or GOLD 2; 0-1 exacerbation per year and no hospitalization due to exacerbation; $\mathrm{CAT} \geq 10$ or $\mathrm{mMRC} \geq 2$

GROUP C - high risk, few symptoms; GOLD 3 or GOLD $4 ; \geq 2$ exacerbations per year or $\geq 1$ hospitalization due to exacerbation; CAT $<10$ or mMRC 0-1

GROUP C - high risk, few symptoms; GOLD 3 or GOLD $4 ; \geq 2$ exacerbations per year or $\geq 1$ hospitalization due to exacerbation; CAT $<10$ or mMRC 0-1

GROUP D - high risk, multiple symptoms; GOLD 3 or GOLD $4 ; \geq 2$ exacerbations per year or $\geq 1$ hospitalization due to exacerbation; CAT $\geq 10$ or $\mathrm{mMRC} \geq 2$

\section{HIIT, parameters and their benefits}

HIIT is becoming popular due to its wide variety of modalities, which can be performed in terrestrial or aquatic environments. For years HIIT was linked only to sports training because it is a high impact modality, but it has been gaining adepts among less active individuals due to the possibility of obtaining gains in a shorter training period. The training consists in increasing the intensity or volume of the exercise for a certain time and reducing it for another determined time, preventing a steady state. ${ }^{15}$ It is recognized for promoting efficiency in a short period of time, inducing positive or even superior systemic alterations when compared with continuous training of moderate intensity. ${ }^{16}$

According to the American College of Sports Medicine (ACSM)15, HIIT can be characterized by an exercise period ranging from 5 to 8 minutes, performed between a target zone from 80 to $95 \%$ of maximal heart rate, with the rest period being equal to the exercise period and performed between 40 and $50 \%$ of maximal heart rate.

The physiological adaptations include an increase in muscle oxidative capacity, improvement in the function of peripheral vascular structures, reduction of glycogen utilization and lactate production during exercise, and a reduction of $\mathrm{O}_{2}$ consumption in submaximal exercises. ${ }^{17}$

Several types of HIIT can be found in the literature, varying according to duration, frequency, intensity of training and rest. Exercise tolerance can be measured by maximal $\mathrm{O}_{2}\left(\mathrm{VO}_{2}\right.$ max), maximal heart rate (HR max) and maximum workload. ${ }^{1}$

Since HIIT is a high impact type of training, a physiotherapist must assess, among other functions, 


\section{Review article}

whether the individual is fit for training, if sufficient peripheral muscle strength exists for the patient to enter the desired aerobic target zone and if there is full understanding of the training to be performed. ${ }^{21,23}$

\section{Pulmonary rehabilitation}

Exercise intolerance is one of the main limiting factors in patients with respiratory diseases. Cardinal symptoms include dyspnea and/or fatigue resulting from limitation of ventilation, gas exchange dysfunction, peripheral muscle impairment and cardiac dysfunction. The limitation in ventilation is due to an increase in the dead lung space provoked by the pathology itself, directly affecting gas exchange, which may cause hypoxia and stimulate the production of lactic acid. Cardiac dysfunction occurs in several ways, but the main one is related to increased pressure generated by the lungs in the chest and pulmonary arteries, resulting in the right ventricle exerting pressure to eject the blood to be oxygenated. ${ }^{18}$

Pulmonary rehabilitation is the gold standard for the treatment of patients with COPD. Its focus is on the reduction of the dysfunctions generated by the disease, as well as the provision of a better quality of life, a reduction in dyspnea, improvements exercise performance and a reduction in the demands on centers and hospitalization. It should be noted that this type of intervention also generates a reduction in the symptomatology when compared to standard pharmacological treatments. Physical training, health education, nutritional education, occupational therapy, psychology and social support are included in integral pulmonary rehabilitation..$^{19,20}$

Health education contributes to the adherence to treatment by patients, to better understand their pathology and how to deal with symptoms through educational activities. It includes the teaching of breathing strategies, assistance in the correct use of supplemental oxygen and medication, teaching of bronchial hygiene techniques, encouragement of physical exercise, preservation of energy and teaching of techniques that can be used to simplify tasks, encouragement of good nutrition and stopping or reducing smoking, prevention of exacerbations and seeking of health care if they occur, encouragement of leisure, travel, and sexuality, strategies such as coping with chronic lung disease and end-of-life planning, anxiety management, and panic attacks, including relaxation techniques and stress management. ${ }^{18,21}$
Improvements in skeletal muscle function after physical training result in gains in exercise capacity. Improved oxidative capacity and skeletal muscle efficiency lead to reduced alveolar ventilation for a given work rate, thereby reducing the hyperinflation of the lungs and reducing dyspnea, as well as improving exercise performance. ${ }^{18}$

In this context, physiotherapy is a component of pulmonary rehabilitation for the treatment of COPD, acting to reduce symptoms, improve the individual's activity and functionality, and promote a better quality of life and independence, with the aim of improving the knowledge of COPD by the patient, besides promoting self-management of the disease. ${ }^{2}$

In addition to the patient's education regarding illness and self-care, aerobic training, strength training and muscular endurance form part of the treatment. Patients, in turn, report significant improvements in their clinical condition, especially in relation to dyspnea. The approach, however, must be multidisciplinary, such that the patient benefits from other forms of therapy, especially the use of bronchodilator medication. $5,13,14$

Regarding the rehabilitation program, physical exercises involving aerobic exercises, particularly of the lower limbs, such as fast walking or a stationary bicycle, should be included for at least 6 weeks. In contrast, long-term programs can also be prescribed and lead to a progressive improvement in quality of life, dyspnea, exercise tolerance and reduction of cardiovascular risks. There is a consensus that at least three sessions per week should be performed in order to maintain progress, of which two should be supervised by a health professional. The duration of each aerobic workout varies, but patients' heart rate should not be less than $60 \%$ of their maximum heart rate. $18,19,34$

As an integral part of pulmonary rehabilitation, specific exercises may be introduced for gaining upper limb strength, such as cycloergometer, free weight and elastic bands or tubes, favoring the improvement of dyspnea when specific activities are required. ${ }^{18}$

The group of patients with COPD that have higher or lower benefits with pulmonary rehabilitation programs is unknown. Improvements in exercise capacity and dyspnea are the most commonly achieved gains with treatment. No justification exists for the exclusion of patients from treatment based on age, dysfunction or smoking status nor any justifications that patients with serious comorbidities, such as cardiac or locomotor impairment, do not 
benefit from treatment. The literature indicates that patients with moderate to severe COPD benefit from an 8-week pulmonary rehabilitation program, with partial maintenance of these benefits for up to one year. ${ }^{19,20,21,22}$

In addition to the aforementioned benefits, pulmonary rehabilitation may reduce the depression and anxiety caused by COPD, regardless of improvements in quality of life and dyspnea. Patients with quadriceps muscle weakness, long-term smokers, and those with depression tend to abandon treatment, but depressed patients tend to evade treatment twice as often as non-depressed patients. ${ }^{23,24}$

The total time of aerobic exercise should not exceed 30 minutes, but more debilitated patients are unable to reach this stipulated minimum time, such that interval training is an alternative, alternating time bands with high and low intensity. In order to improve exercise performance, supplemental oxygen may be used during the activity, as well as the use of bronchodilators in individuals with limitation of airflow subject to medical prescription. ${ }^{18,20}$

Pulmonary rehabilitation, therefore, becomes essential for the management of patients with COPD. ${ }^{21}$

\section{Systemic effects of HIIT}

Overall, aerobic physical exercise is clinically proven to be a primary intervention that slows and, in many cases, prevents health-related expenditures on various chronic diseases. The type of exercise and the amount of cumulative health benefits is a matter without clear recommendations for the prevention of disorders related to chronic diseases. HIIT can stimulate physiological remodeling when compared to continuous training of moderate intensity, despite the shorter time spent in training. ${ }^{16}$

HIIT is usually achieved through the use of intervals, in contrast with other types of submaximal training that are characterized by prolonged and continuous activity. HIIT can be broadly defined as repeated episodes of short to moderate duration exercise completed at an intensity above the anaerobic threshold. Exercise shifts are separated by brief periods of low intensity work or inactivity that allow partial, but in most cases not complete, recovery. ${ }^{25}$

In this review, HIIT is advocated for groups of individuals with COPD, who are mostly sedentary. Therefore, sedentary individuals with HIIT improve resistance performance to a greater extent than with continuous submaximal training alone, and this improvement may be related to the regulated contribution of aerobic and anaerobic metabolism to energy demand, which increases the availability of adenosine triphosphate (ATP) and improves the state of energy in working muscles. There is evidence of an increase in type I fibers, capillarization and oxidative enzymatic activity, which are the most common HIT responses in untrained or moderately active individuals. $^{25}$

Peripheral adaptations in exercising HIIT refer to an improved ability to work muscles for the production and use of ATP. Increased glycogenolytic capacity is another explanation for the improvement in exercise resistance. ${ }^{5,22,25}$

The factors responsible for the improvement in exercise capacity induced by training are complex and determined by numerous physiological elements of a cardiovascular, ionic, metabolic, neurological and respiratory nature, while influenced by humor, motivation and perception of effort. However, fundamental questions remain about the minimum volume of exercises needed to improve physiological well-being in various populations, on the effectiveness of alternative (less extreme) training strategies, and the adaptations that can be acquired and maintained over the long term. ${ }^{26}$

Little et al. (2010) ${ }^{27}$ demonstrated that a modified low volume training in HIIT is a potent stimulus for the increase of mitochondrial skeletal muscle capacity, improving exercise performance.

In previously untrained individuals, exerciseinduced cellular hypoxia increases blood flow, $\mathrm{O}_{2}$ distribution, oxygen extraction and fat metabolism in muscles. As a result, muscle contraction becomes more efficient and the capacity for physical exercise is increased..$^{25}$

The influence of training modalities on mitochondrial function, capillary networks and its role in the configuration of the capacity to promote aerobic performance were not explored, and the relationship between cardiac output and the increase in $\mathrm{VO}_{2}$ max was still little studied. ${ }^{28}$

The manipulation of the intensity and duration of training and rest intervals alter the relative demands on particular metabolic pathways within the muscle cells, as well as the delivery of $\mathrm{O}_{2}$ to the muscle. Therefore, adaptations occurring subsequent to training, both at the cellular and systemic level, are specific to the particular characteristics of the training program employed..$^{25}$ 
Daussin et al. (2008) ${ }^{28}$ showed that a constant workload and $\mathrm{O}_{2}$ consumption during continuous training induce a greater increase in muscle capillary density when compared to interval training.

The high and variable workload and the $\mathrm{O}_{2}$ consumption during interval training improved the skeletal muscle mitochondrial function as well as the arteriovenous difference after both training modalities, but only interval training induced a significant increase in Qmax. Significant relationships between Qmax and $\mathrm{VO}_{2}$ max were found only after interval training. ${ }^{28}$

There is considerable debate about which training program (continuous or interval) has the best impact on aerobic performance. Continuous training is characterized by constant power and $\mathrm{O}_{2}$ consumption, while interval training alternates periods of low and high mechanical power, with fluctuations in $\mathrm{O}_{2}$ consumption. The specific mechanisms that guide the oxidative adaptations in the muscles, together with the central and peripheral alterations, remain little clarified..$^{28}$

HIIT promotes aerobic capacity benefits. The "rest" times of this training modality means that practitioners do not over-wear and tolerate higher levels of intensity when compared with moderate continuous training. Even in a shorter time, HIIT can promote equivalent effects to conventional training. ${ }^{2,6,23}$

\section{HIIT in Chronic Obstructive Pulmonary Disease}

In a randomized controlled clinical trial, Vogiatzis et al. (2002) ${ }^{29}$ compared the effect of two aerobic training protocols on quality of life and exercise tolerance in patients with COPD and moderate to severe airflow limitation. The study demonstrated that interval training provides benefits equivalent to continuous training, which was performed at $50 \%$ of the intensity used by HIIT, but used twice the time. The program used included a multidisciplinary (physiotherapy, pulmonology, nutrition and psychiatry) team. In addition to the protocols, patients were instructed to exercise their trunk musculature at home with respiratory exercises, strengthening the importance of guidelines related to the pulmonary rehabilitation program with scoring according to the GOLD initiative.

Puhan et al. (2006) ${ }^{30}$ proposed to identify which aerobic training model could be best prescribed for individuals with COPD at GOLD III to IV. They observed that no statistically significant difference exists between interval training (IT) and continuous training $(\mathrm{CT})$ in terms of improved quality of life and exercise tolerance in these patients. This study focused on the difficulty of patients to initiate physical training under supervision, so there was a tendency of patients who performed IT (47.9\%) to adhere better to the protocol than patients who underwent CT $(24.0 \%)(p=0.014)$. The mean number of involuntary breaks (lasting 1 minute or more) in interval training was only 2 cases in interval training and 11 cases in continuous training $(p=0.023)$. At discharge, aerobic exercises were prescribed for each patient performing daily, comprising 20 minutes (cycle ergometer, swimming, climbing / descending stairs). However, the present study focused only on patients under supervision and not on the external environment, making a follow-up evaluation impossible. This study pointed out that interval training had a higher rate of acceptance, although both types of training sessions could be prescribed in accordance with patient acceptance and preference.

Arnardóttir et al. (2007) ${ }^{31}$ aimed to compare the effects of an interval training program with continuous training in patients with moderate to severe COPD. Once a week, after training, the patients performed calisthenic exercises and relaxation, while on the other day of this week they participated in resistance exercises that in the whole completed 90-minute sessions. After the training period, both groups increased, without significant differences, their maximum working capacity, maximum absorption of $\mathrm{VO}_{2}$ and maximum exhalation of $\mathrm{CO}_{2}$. The minute volume increased only in the CT group. Functional capacity, dyspnea, quality of life, mental health and quality of life improved significantly in both groups, with no significant differences.

Mador et al. (2009) ${ }^{32}$ conducted a randomized clinical trial of 41 individuals with severe airflow obstruction. Regarding the outcomes analyzed (distance walked in a 6-minute walking test, maximum work capacity, duration of resistance exercise, quality of life, fatigue and dyspnea), all variables showed improvements that did not differ significantly between groups. Compared to the group that performed continuous aerobic training, the IT group obtained good tolerance rates and produced similar improvements in exercise performance and quality of life.

\section{Conclusion}

The natural course of COPD is characterized by progressive airflow limitation, repetitive exacerbation 
and respiratory failure. Pulmonary rehabilitation works in a multidisciplinary way and the professional physiotherapist is directly related to improvements in the quality of life related to mechanical and physical aspects, an increase in tolerance to exercise and a reduction in dyspnea.

In general, exercise tolerance in patients with COPD is directly related to the development of dynamic hyperinflation, concomitantly with mechanical restrictions caused by ventilatory changes. Associated with the dynamic hyperinflation presented and the increase in the mean intrathoracic pressure caused by air trapping, cardiac performance and, consequently, the supply of oxygenated blood to the peripheral musculature are impaired, hindering tolerance to exercise and promoting fatigue, especially in the lower limb musculature.

Interval training uses exercise shifts, sometimes of high intensity, sometimes reduced, which allow a sufficient load on the peripheral muscles for enough time to obtain the desired effects of the physiological training, promoting better adhesion to high intensity exercise.

The present review concludes that high-intensity interval training may provide a good alternative for use in the pulmonary rehabilitation of patients with moderate to severe COPD. HIIT was well accepted by patients and, in general, presented similar effects to continuous training with regard to quality of life, dyspnea and exercise tolerance. In general, none of the modalities of aerobic exercise employed in the treatment of COPD patients is clearly superior, but exercises exist that best fit each patient's profile. However, a study of new interval training protocols is required to evaluate both the efficacy and applicability of this training modality in patients with COPD.

Finally, one must consider some of the limitations of this study. The search for articles was restricted to just three databases. So, although these were strong bases for the selection of articles related to the topic, potentially relevant studies were probably not part of the evaluated sample. The insertion of systematic reviews and meta-analyzes was not provided for in the present study. The number of articles analyzed was relatively low, hindering a more incisive conclusion on the subject. However, it was possible to describe this aerobic training modality through a sample considered as representative, enabling the discussion of HIIT in the pulmonary rehabilitation of patients with COPD.

\section{References}

1. Global Initiative for Chronic Obstructive Lung Disease (GOLD). Global strategy for the diagnosis, management, and prevention of chronic obstructive pulmonary disease. 2016. $34 p$.

2. Troosters T, Casaburi R, Gosselink R, et al. Pulmonary rehabilitation in chronic obstructive pulmonary disease. Am J Respir Crit Care Med. 2005 Jul 1;172(1):19-38.

3. Langer D, Probst VS, Pitta F, et al. Guia para prática clínica: fisioterapia em pacientes com Doença Pulmonar Obstrutiva Crônica (DPOC). Rev Bras Fisioter. 2009;13(3):183-204.

4. Cardoso AP. Exacerbação da DPOC. Sumário Content, 2013;22(2):6460.

5. Berg K, Wright JL. The pathology of chronic obstructive pulmonary disease: progress in the 20th and 21 st centuries. Arch Pathol Lab Med. 2016 Dec;140(12):1423-1428.

6. Rodriguez DA, Garcia-Aymerich J, Valera JL, et al. Study Group. Determinants of exercise capacity in obese and nonobese COPD patients. Respir Med.. 2014;108(5):745-51.

7. Sousa TC, Jardim JR, Jones P. Validação do Questionário do Hospital Saint George na Doença Respiratória (SGRQ) em pacientes portadores de doença pulmonar obstrutiva crônica no Brasil. J Pneumologia. 2000 Mai/Jun;26(3):119-28.

8. Silva GPF, Morano MTAP, Viana CMS, et al. Portugueselanguage version of the COPD Assessment Test: validation for use in Brazil. J Bras Pneumol.. 2013;39(4):402-8.

9. Kovelis D, Segretti NO, Probst VS, et al. Validação do Modified Pulmonary Functional Status and Dyspnea Questionnaire e da escala do Medical Research Council para o uso em pacientes com doença pulmonar obstrutiva crônica no Brasil. J Bras Pneumol. 2008;34(12):1008-18.

10. Molen T, Willemse BW, Schokker S, et al. Development, validity and responsiveness of the Clinical COPD Questionnaire. Health and qual life out. 2003;1(1):13.

11. Jones PW, Forde Y. St George's Respiratory Questionnaire for COPD Patients (SGRQ-C) Manual 2008. Division of Cardiac and Vascular Science. UK: St George's, University of London. Health Related Quality. 2008.

12. Moreira GL, Pitta F, Ramos $D$, et al. Versão em português do Chronic Respiratory Questionnaire: estudo da validade e reprodutibilidade. J Bras Pneumol. 2009;35(8):737-44.

13. Stendardi L, Binazzi B, Scano G. Exercise dyspnea in patients with COPD. International journal of chronic obstructive pulmonary disease. 2007;2(4):429.

14. Daabis R, Hassan M, Zidan M. Endurance and strength training in pulmonary rehabilitation for COPD patients. Egyptian Journal of Chest Diseases and Tuberculosis. 2016;66(2):231-6.

15. American College of Sports Medicine (ACSM). High-intensity interval training: 2014. AMERICAN COLLEGE OF SPORTS MEDICINE. Disponível em: www.acsm.org.

16. Gibala MJ, Little JP, MacDonald MJ, et al. Physiological adaptations to low-volume, high-intensity interval training in health and disease. J Physiol. 2012;590(5):1077-84.

17. Gibala MJ, Jones AM. Physiological and performance adaptations to high-intensity interval training. Nestle Nutr Inst Workshop Ser. 2013;76:51-60.

18. Nici L, Donner C, Wouters E, et al. American thoracic society/ European respiratory society statement on pulmonary rehabilitation. American journal of respiratory and critical care medicine. 2006;173(12):1390-1413 


\section{Review article}

19. Jones R. British thoracic society standards of care subcommittee on pulmonary rehabilitation. Thorax. 2001;56(56):827-34.

20. Wehrmeister FC, Knorst M, Jardim JR. et al. Programas de reabilitação pulmonar em pacientes com DPOC. J Bras Pneumol. 2011;37(4):544-555.

21. Nascimento AO, lamonti VC, Jardim JR. Reabilitação pulmonar. Sumário Content. 2013;22(2):6965

22. Ries AL, Kaplan RM, Limberg TM, et al. Effects of pulmonary rehabilitation on physiologic and psychosocial outcomes in patients with chronic obstructive pulmonary disease. Ann Intern Med. 1995;122(11):823-32.

23. Garrod R, Marshall J, Barley E, et al. Predictors of success and failure in pulmonary rehabilitation. Eur Resp J. 2006;27(4):788-94.

24. Paz-Díaz H, Montes OM, Lopez JM, et al. Pulmonary rehabilitation improves depression, anxiety, dyspnea and health status in patients with COPD. Am J Phys Med Rehabil. 2007;86(1):30-6.

25. Laursen PB, Jenkins DG. The scientific basis for high-intensity interval training. Sports Med. 2002;32(1):53-73.

26. Gibala MJ, McGee SL. Metabolic adaptations to short-term high-intensity interval training: a little pain for a lot of gain? Exerc Sport Sci Rev. 2008;36(2):58-63.
27. Little GP, Safdar A, Wilkin GP, et al. A practical model of lowvolume high-intensity interval training induces mitochondrial biogenesis in human skeletal muscle: potential mechanisms. J Physiol. 2010;588(6):1011-22.

28. Daussin FN, Zoll J, Dufour SP, et al. Effect of interval versus continuous training on cardiorespiratory and mitochondrial functions: relationship to aerobic performance improvements in sedentary subjects. Am J Physiol Regul Integr Comp Physiol. 2008;295(1):r264-r272.

29. Vogiatzis I, Nanas S, Roussos C. Interval training as an alternative modality to continuous exercise in patients with COPD. Eur Respir J. 2002;20(1):12-19.

30. Puhan MA, Busching G, Schunemann $\mathrm{HJ}$, et al. Interval versus continuous high-intensity exercise in chronic obstructive pulmonary disease: a randomized trial. Ann Intern Med. 2006;145(11):816-25.

31. Arnardóttir RH, Boman G, Larsson K, et al. Interval training compared with continuous training in patients with COPD. Respir Med. 2007;101(6):1196-1204.

32. Mador MJ, Krawza M, Alhajhusian A, et al. Interval training versus continuous training in patients with chronic obstructive pulmonary disease. J Cardiopulm Rehabil. 2009;29(2):126-32. 